This is the peer-reviewed version of the article:

Obradović, N., Blagojević, V., Filipović, S., Đorđević, N., Kosanović, D., Marković, S., Kachlik, M., Maca, K., Pavlović, V., 2018. Kinetics of thermally activated processes in cordierite-based ceramics. Journal of Thermal Analysis and Calorimetry.

https://doi.org/10.1007/s10973-018-7924-1

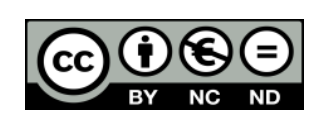

This work is licensed under the

Attribution-NonCommercial-NoDerivatives 4.0 International (CC BY-NC-ND 4.0) 


\title{
Kinetics of thermally activated processes in cordierite-based ceramics
}

\author{
Nina Obradović ${ }^{*}$, Vladimir Blagojević ${ }^{1}$, Suzana Filipović ${ }^{1}$, Nataša Đorđević ${ }^{2}$, \\ Darko Kosanović1, Smilja Marković ${ }^{1}$, Martin Kachlik ${ }^{3}$, Karel Maca ${ }^{3}$, Vladimir Pavlović1 \\ ${ }^{1}$ Institute of Technical Sciences of SASA, Knez Mihailova 35/IV, 11000 Belgrade, Serbia \\ ${ }^{2}$ Institute for Technology of Nuclear and Other Mineral Raw Materials, \\ Bulevar Franse d'Eperea 86, 11000 Belgrade, Serbia \\ ${ }^{3}$ CEITEC BUT, Brno University of Technology, Purkynova 123, 61200 Brno, \\ Czech Republic
}

\begin{abstract}
Thermally activated processes in cordierite-based ceramics were investigated to determine the effect of the mechanical activation and the addition of $\mathrm{TeO}_{2}$ on kinetic and thermodynamic parameters of these processes. Using a combination of dilatometry and DTA measurements in the $100-1400^{\circ} \mathrm{C}$ temperature range, it was established that both the mechanical activation and the addition of $\mathrm{TeO}_{2}$ have a significant effect on processes in cordierite-based ceramics. A combination of 5 mass $\%$ addition of $\mathrm{TeO}_{2}$ and mechanical activation for 40 minutes reduced the sintering temperature of cordierite ceramics to around $1100{ }^{\circ} \mathrm{C}$. In addition, the analysis of DTA measurements of mechanically activated samples indicates that the mechanical activation leads to intensification of the cordierite formation through an increase in concentration of surface defects and an increase in grain contact surface in the initial powder.
\end{abstract}

Keywords: Mechanical activation; DTA; sintering kinetics; cordierite; $\mathrm{TeO}_{2}$.

\section{Introduction}

Cordierite, with $2 \mathrm{MgO}+2 \mathrm{Al}_{2} \mathrm{O}_{3}+5 \mathrm{SiO}_{2}$ composition, is a ceramic material that possesses a low dielectric constant $(\sim 5)$ and low thermal expansion coefficient $\left(20 \cdot 10^{-7}{ }^{\circ} \mathrm{C}^{-1}\right)$, making it useful in thermal shock applications, and as a carrier of electronic components as a dense ceramic material [1-11]. Owing to its lower processing cost and better electrical properties, cordierite represents an alternative to alumina in electronic applications [12].

*Corresponding author: nina.obradovic@itn.sanu.ac.rs (Dr. Nina Obradović) 
On the other hand, porous cordierite and mullite ceramics have an important application as

filters for diesel emission, molten metals, and devices where chemical durability and permeability at high temperatures are required [13-15]. However, cordierite exhibits a very narrow sintering window close to its melting point $\left(1470{ }^{\circ} \mathrm{C}\right)$, necessitating the use of sintering aids and/or mechanical activation to reduce its sintering temperature.

Mechanical activation and sintering aids have a significant effect on the sintering process [16-19]. The process of mechanical activation is beneficial for ultra fine grinding of starting powders prior to synthesis of various types of materials [20], and has a strong influence on physical, chemical, and physico-chemical properties of milled materials due to the transfer of mechanical energy into the powder [21]. During mechanical activation, several processes take place within the material: attrition of starting components, increase in overall free energy of the system, changes in crystal lattice, phase transformation, possible chemical reactions, and appearance of intermediate compounds or even final chemical products [22-24]. In addition, the sintering temperature can be lowered and the time needed for chemical reaction shortened. However, the nature of these modifications is not still well defined, mainly due to the highly specific and multiparameter nature of disperse systems. Additives are added to the starting powder mixtures in order to lower the sintering temperature, accelerate the process of obtaining the final product, and getting the product with targeted properties.

There has been a broad effort to improve the solid state reaction in cordierite-based ceramics, reducing the sintering temperature by adding different functional additives, e.g., $\mathrm{Bi}_{2} \mathrm{O}_{3}$, yttrium-stabilized zirconia, ceria, $\mathrm{B}_{2} \mathrm{O}_{3}, \mathrm{P}_{2} \mathrm{O}_{5}, 2 \mathrm{MgO} \cdot \mathrm{B}_{2} \mathrm{O}_{3}, \mathrm{TiO}_{2}, \mathrm{MoO}_{3}$, etc. [9, 25-29], which managed to lower the cordierite sintering temperature to the $1200-1350{ }^{\circ} \mathrm{C}$ temperature range. In particular, doping with 3 wt. $\%$ of $\mathrm{B}_{2} \mathrm{O}_{3}$ and $\mathrm{P}_{2} \mathrm{O}_{5}$ has been shown to reduce the sintering temperature to about $1000{ }^{\circ} \mathrm{C}$ and produce a material with a low dielectric constant and low dissipation factor, which are favorable traits for high-frequency applications [26].

According to available literature data, there have been no reports on $\mathrm{TeO}_{2}$ addition to the cordierite mixture and its influence on the sintering temperature. Physico-chemical properties of $\mathrm{TeO}_{2}$ and its relatively low melting and boiling points (around $733{ }^{\circ} \mathrm{C}$ and $1245{ }^{\circ} \mathrm{C}$, respectively) motivated us to investigate its potential as an additive to the cordierite mixture [30]. The position of the boiling point of $\mathrm{TeO}_{2}$ close to the potential sintering window of cordierite could result in a more porous ceramic material. Use of a single substance to achieve both a porous ceramic material and lower sintering temperature would significantly simplify the potential industrial production.

In this paper, the effects of mechanical activation along with $\mathrm{TeO}_{2}$ addition on formation of porous ceramics, densification, and reduction of the sintering temperature of cordierite ceramics were analyzed using a combination of dilatometric and DTA measurements. Isoconversional Ortega 
method was used to determine the relevant kinetic and thermodynamic parameters, allowing prediction of the optimal sintering conditions to obtain a material with targeted functional properties.

\section{Experimental procedure}

Mixtures of $\mathrm{MgO}, \mathrm{Al}_{2} \mathrm{O}_{3}, \mathrm{SiO}_{2}$, and $\mathrm{TeO}_{2}$ (all $99 \%$ p.a. Sigma-Aldrich) were used in these experiments. Starting powders were firstly calcined at $700{ }^{\circ} \mathrm{C}$ for $2 \mathrm{~h}$ in a tube furnace, in order to eliminate hydroxides, mainly $\mathrm{Mg}(\mathrm{OH})_{2}$ and $\mathrm{Al}(\mathrm{OH})_{3}$. The mixtures of $\mathrm{MgO}+\mathrm{Al}_{2} \mathrm{O}_{3}+\mathrm{SiO}_{2}$ in the 2:2:5 molar ratio, with and without the addition of 5 mass $\% \mathrm{TeO}_{2}$, were mechanically activated by grinding in a high-energy planetary ball mill, with $400 \mathrm{rpm} . \mathrm{ZrO}_{2}$ vessels and balls were used with the powder to balls mass ratio of 1:40. The milling process was performed in air for 10 and 40 minutes. The samples were denoted as MAS-0, MAS-10, MAS-40, MAS-Te-0, MAS-Te-10, and MAS-Te-40 (according to the activation time and $\mathrm{TeO}_{2}$ addition).

The X-ray powder diffraction patterns of the starting powders and their mixtures were obtained using a Philips PW-1050 diffractometer with $\lambda \mathrm{Cu}-\mathrm{K}_{\alpha}$ radiation and a step/time scan mode of $0.05 \mathrm{deg} \mathrm{s} \mathrm{s}^{-1}$. The measurements were performed at room temperature in air atmosphere. The quantity content of all present samples was evaluated by HighScore (PANalytical) software. The morphology of the sintered samples was analyzed by the scanning electron microscopy (JEOL JSM-6390 LV). Prior to SEM measurements, the samples were crushed and covered with gold.

Average particle size and particle size distribution were determined by a laser light-scattering particle size analyzer (PSA). The used instrument was Mastersizer 2000 (Malvern Instruments Ltd., UK) particle size analyzer, covering the particle size range of $0.02-2000 \mu \mathrm{m}$. For the PSA measurements, the powders were dispersed in distilled water, in ultrasonic bath (low-intensity ultrasound, at a frequency of $40 \mathrm{kHz}$ and power of $50 \mathrm{~W}$ ), for 5 minutes.

Thermal behavior of starting powders and their mixtures was determined by simultaneous TG-DTA (Setsys, SETARAM Instrumentation, Caluire, France) in the temperature range between 25 and $1400{ }^{\circ} \mathrm{C}$ under the air flow of $20 \mathrm{ml} \mathrm{min}^{-1}$, in an $\mathrm{Al}_{2} \mathrm{O}_{3}$ pan. Experiments were done by heating rates of 10,20 , and $30{ }^{\circ} \mathrm{C} \mathrm{min}^{-1}$. Peak deconvolution and kinetic analyses were performed using ThermV v0.2 software package [31]. The conversion degree $\alpha$ is calculated for each peak as the ratio of the partial peak surface area at a given temperature to the surface area of the entire peak, providing the measure of the fraction of converted reactant at that particular point.

The study of densification of green bodies made from different powder mixtures was performed via dilatometry measurements. The green bodies were formed by uniaxial pressure of 
$20 \mathrm{MPa}$ (diameter of die was $16 \mathrm{~mm}$ ) and followed by cold isostatic pressuring at $300 \mathrm{MPa}$. The dilatation (shrinkage) of the samples was measured on L75/Platinum (Linseis, Germany) hightemperature dilatometer. The final sintering temperature was $1350{ }^{\circ} \mathrm{C}$ with dwell time 1 hour, and the heating/cooling rates were both $10{ }^{\circ} \mathrm{C} \mathrm{min}^{-1}$. The measurements were performed in air atmosphere. The measuring piston setup was made from $\mathrm{Al}_{2} \mathrm{O}_{3}$ ceramics. The shrinkage was transformed into the density vs. time (resp. temperature) dependence according to the procedure described elsewhere [32] using measurement of the final apparent density of the samples according to Archimedes' principle in water media (EN 623-2).

\section{Results and discussion}

Figure 1 shows the particle size distribution for all samples. The average particle size distribution for non-activated powder MAS-0 was $4.716 \mu \mathrm{m}$. With mechanical activation of 10 minutes, it decreased to 4.455 , while after 40 minutes, the value was $4.073 \mu \mathrm{m}$, indicating particle size reduction during milling.
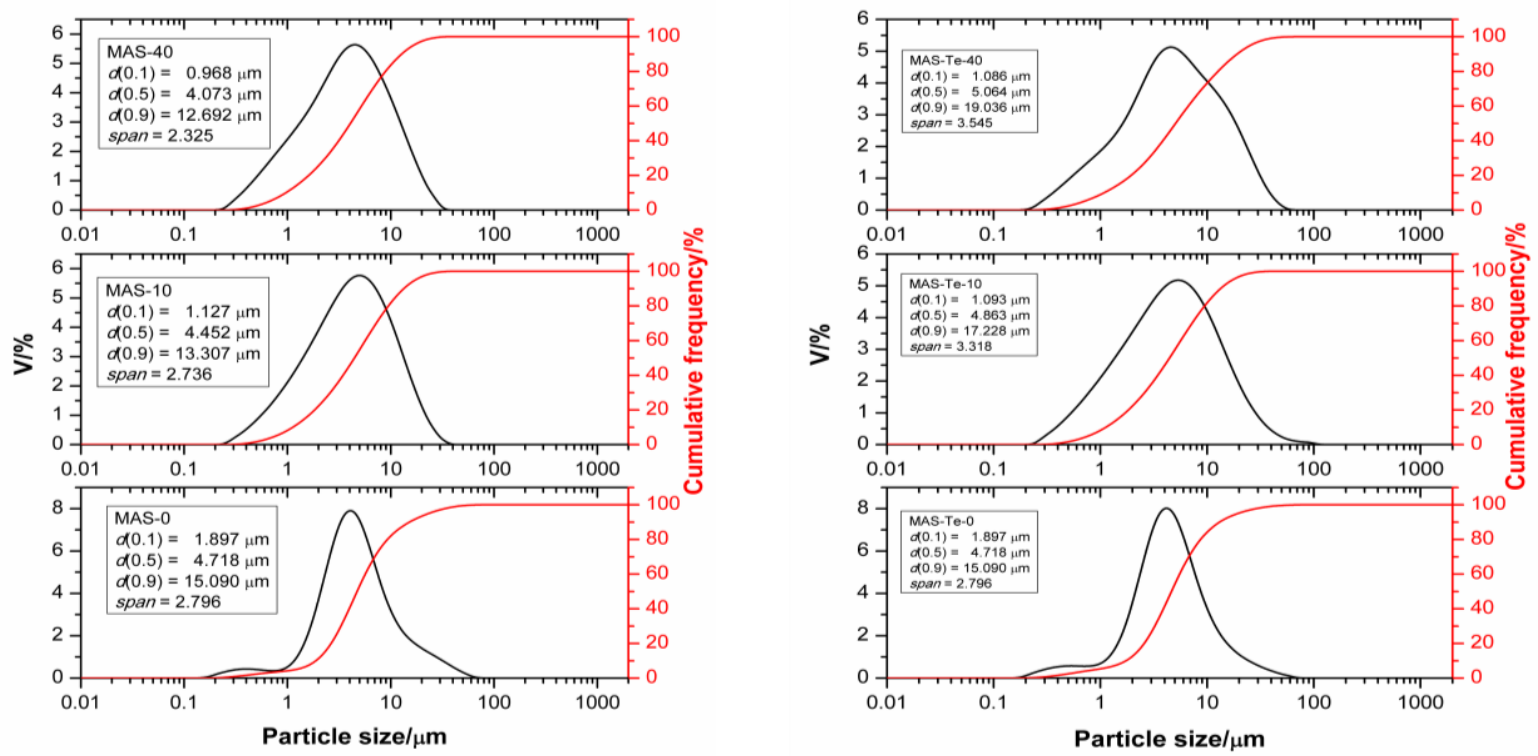

a)

b)

Figure 1 Particle size analysis for a) samples without $\mathrm{TeO}_{2}$, and b) samples with $\mathrm{TeO}_{2}$ addition [33].

In powders with the addition of $\mathrm{TeO}_{2}$, that trend was not observed: $\mathrm{d}(0.5)$ slightly increased with increased mechanical activation, from 4.718 to 4.863, and to 5.064, for MAS-Te-0, MAS-Te10, and MAS-Te-40, respectively [33]. Based on these results, and trends for $\mathrm{d}(0.1)$ and $\mathrm{d}(0.9)$, we 
can conclude that the size of agglomerates and average particles in doped samples increased with the mechanical activation, while smaller particles are decreased.

Phase composition of starting components and all investigated mixtures is presented in Figure 2. All diffraction lines are identified using corresponding JCPDS cards (74-1081 for $\alpha$ $\mathrm{Al}_{2} \mathrm{O}_{3}, 89-6092$ for $\beta-\mathrm{Al}_{2} \mathrm{O}_{3}, 77-2364$ for $\mathrm{MgO}, 71-0197$ for $\alpha-\mathrm{SiO}_{2}, 76-0679$ for $\alpha-\mathrm{TeO}_{2}$, and 760526 for $\mathrm{MgSiO}_{3}$ ). XRD patterns of alumina and magnesium oxide show the existence of sharp and intensive peaks, indicating that a crystallization process occurred during calcinations of these two powders (heating at $700{ }^{\circ} \mathrm{C}$ for $2 \mathrm{~h}$ in order to avoid hydroxides, which could further affect the stoichiometry). XRD pattern of $\mathrm{SiO}_{2}$ shows no clear peak intensities, but a hump, meaning that the $\mathrm{SiO}_{2}$ phase is in an amorphous state, while $\alpha-\mathrm{TeO}_{2}$ is in a crystal shape (see Figure 2a).
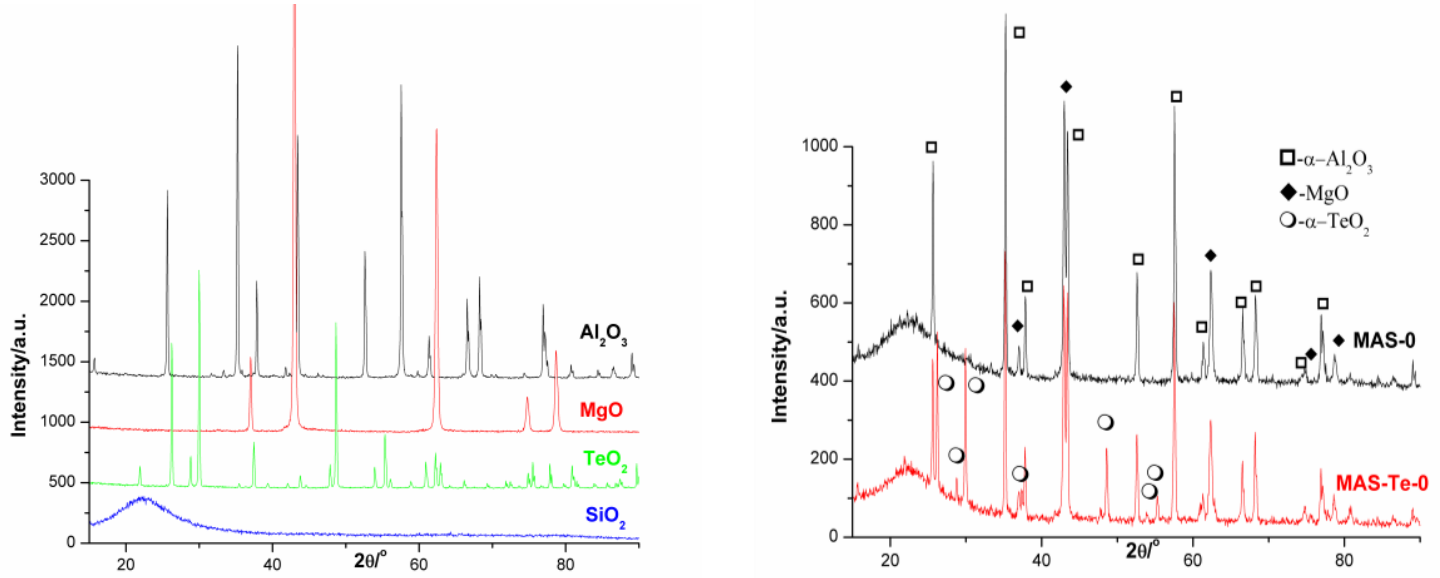

a)

b)
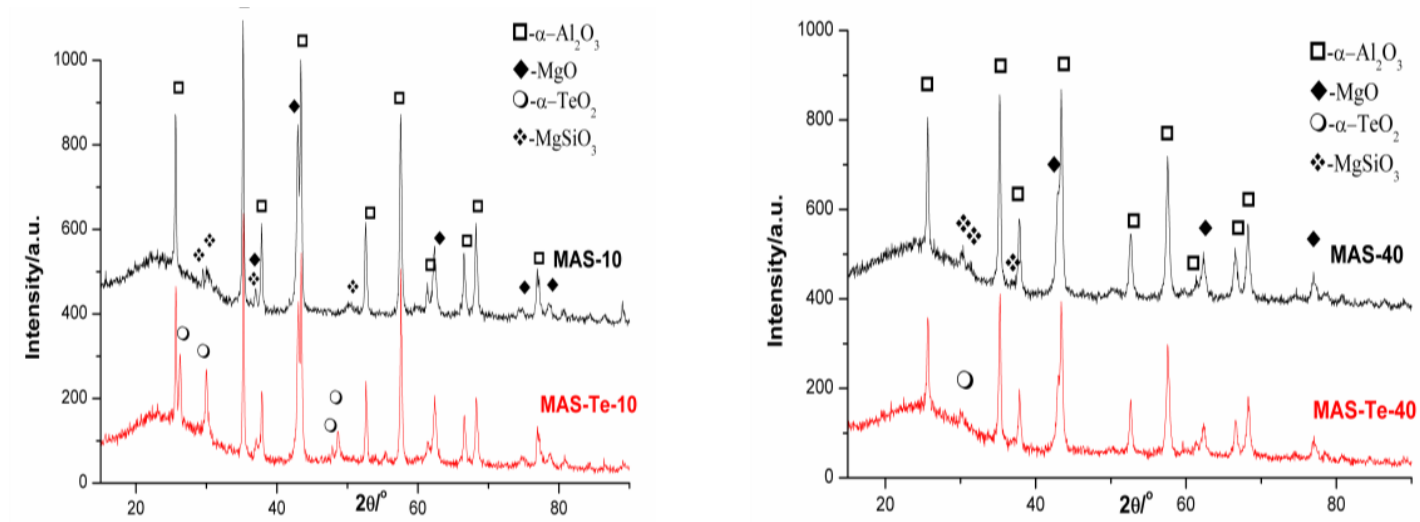

c)

Figure 2 XRD patterns of a) initial powders, b) non-activated mixtures, c) mixtures activated for 10 minutes, and d) mixtures activated for 40 minutes [33].

Within the non-activated sample MAS- -0 , a mixture of starting oxides was detected $(\alpha$ $\mathrm{Al}_{2} \mathrm{O}_{3}, \mathrm{MgO}$, and $\mathrm{SiO}_{2}$ ). Peaks of $\beta-\mathrm{Al}_{2} \mathrm{O}_{3}$ were not detected owing to their low intensity and overlapping with $\mathrm{SiO}_{2}$ peaks. The mixture MAS-Te-0 consisted of all starting powders, including 
$\mathrm{TeO}_{2}$. The first traces of a new phase, $\mathrm{MgSiO}_{3}$, were detected within MAS-10 mixture. After 40 minutes of activation, all phases were present along with a greater quantity of newly formed magnesium silicate (33.5 vol. \%) [33]. Furthermore, peak intensities were lowered along with very slight broadening, which is characteristic for mechanically activated powders, as a result of attrition of particles and intensive introduction of defects into the crystal lattices during intensive and prolonged milling. Pattern of MAS-Te-10 possessed no $\mathrm{MgSiO}_{3}$ peaks. We assume that during milling $\mathrm{TeO}_{2}$ particles gathered around $\mathrm{MgO}$ and/or $\mathrm{SiO}_{2}$ particles and disabled them to be in a direct contact. Therefore, the mechanochemical reaction was omitted. After 40 minutes, magnesium silicate was present with $11.0 \mathrm{vol} \%$ in the mixture with $\mathrm{TeO}_{2}$ addition, along with all other powders. Lowered intensities were present here as well, indicating a crystal lattice destruction of all present powders.

Figure 3 shows the absolute density vs. time, and temperature dependence calculated from dilatometric data.

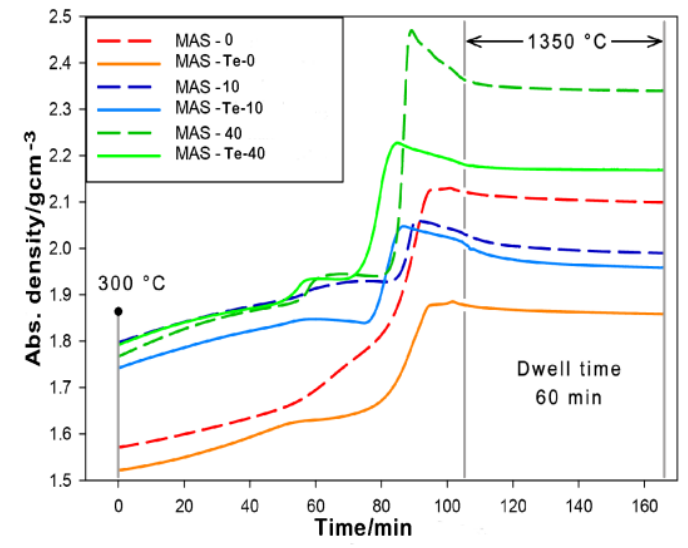

a)

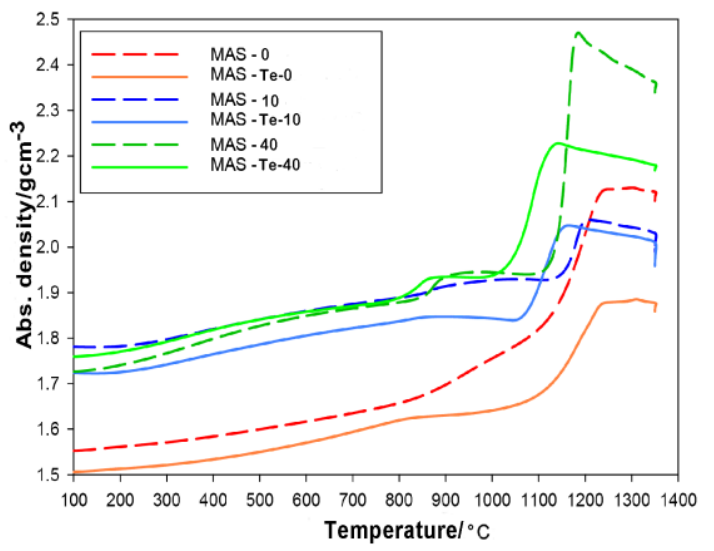

b)

Figure 3 Dilatometry curves presented as a) changes in absolute densities vs. time, and b) temperature for samples activated for 0,10 , and 40 minutes, with and without $\mathrm{TeO}_{2}$.

Dilatometry showed that the density increased with milling. Also, the dilatometric data confirmed that $\mathrm{TeO}_{2}$ doping leads to formation of more porous ceramics. Further, it was observed that sintering occurs at lower temperatures (between 1000 and $1200{ }^{\circ} \mathrm{C}$, depending on the sample), due to the lower melting point of $\mathrm{TeO}_{2}$, according to dilatometric data. The effect of mechanical activation was visible on green densities. The mechanically activated samples started with a similar green density (higher than $1.7 \mathrm{~g} \mathrm{~cm}^{-3}$, mixtures with similar pressing characteristics). Non-activated samples (MAS-0, and MAS-Te-0) started with the green density significantly lower than the activated samples (bellow $1.6 \mathrm{~g} \mathrm{~cm}^{-3}$, see the left end in Figure 1). It is a common behavior for mechanically activated powders, to achieve higher green density when compacted [34]. A phase 
transition was observed in the temperature range $800-900{ }^{\circ} \mathrm{C}$ in the case of samples with higher cordierite phase content (samples activated for 40 minutes - green lines), which was accompanied by an increase in sample density. On the other hand, a decrease in the density of mechanically activated samples was observed between 1100 and $1350{ }^{\circ} \mathrm{C}$, most likely caused by the ongoing solid state reaction, which significantly slowed down soon after the dwell time started. We assume that a dwell time extension would not lead to the completion of the solid state reaction without an additional change in external conditions (increased temperature, application of an isostatic pressure, etc.). The dilatometric analysis of sintering showed that the lowest sintering/reaction temperature was exhibited by the sample activated for 40 minutes, with addition of $\mathrm{TeO}_{2}$ (after 85 minutes heating, around $1100{ }^{\circ} \mathrm{C}$ ), with generally significantly higher impact of the mechanical activation on the sintering temperature than for samples without $\mathrm{TeO}_{2}$.

Table 1 Green and absolute densities, and relative open porosities of sintered samples.

\begin{tabular}{|c|c|c|c|}
\hline Sample & $\begin{array}{c}\text { Green densities } \\
\left(\mathbf{g ~ c m}^{-3}\right)\end{array}$ & $\begin{array}{c}\text { Absolute densities } \\
\left(\mathbf{g ~ c m}^{-\mathbf{3}}\right)\end{array}$ & $\begin{array}{c}\text { Relative open } \\
\text { porosity (\%) }\end{array}$ \\
\hline MAS-0 & 1.55 & 2.10 & 21.9 \\
\hline MAS-10 & 1.79 & 1.99 & 25.4 \\
\hline MAS-40 & 1.73 & 2.34 & 9.9 \\
\hline MAS-Te-0 & 1.51 & 1.86 & 30.5 \\
\hline MAS-Te-10 & 1.72 & 1.96 & 26.2 \\
\hline MAS-Te-40 & 1.77 & 2.17 & 16.8 \\
\hline
\end{tabular}

The highest density $\left(2.34 \mathrm{~g} \mathrm{~cm}^{-3}\right)$ after sintering was reached in the case of the sample MAS-40 (see Table 1). In milled samples, particles were smaller, with larger specific surface areas, which were also more active due to the increased number of defects, caused by milling. Therefore, the diffusion processes were made easier, leading to higher reactivity and more compact samples. All three samples doped by $\mathrm{TeO}_{2}$ exhibit consistently lower densities than the un-doped samples. Having in mind that the boiling point of $\mathrm{TeO}_{2}$ is around $1245^{\circ} \mathrm{C}$ [30], lower than the sintering temperature, it is most likely that during the sintering process, evaporated $\mathrm{TeO}_{2}$ formed bubbles, creating small pores within samples, which remained inside the samples after cooling.

The XRD analyses were performed on sintered samples, and the Rietveld method was used for determining the phase composition quantity. All diffraction lines were identified using corresponding JCPDS cards (75-1439 for $\mathrm{Mg}_{2} \mathrm{Al}_{4} \mathrm{Si}_{5} \mathrm{O}_{18}, 76-0941$ for $\beta-\mathrm{SiO}_{2}$, 89-1625 for $\mathrm{Mg}_{2} \mathrm{SiO}_{4}, 81-2267$ for $\alpha-\mathrm{Al}_{2} \mathrm{O}_{3}$, and 83-0679 for $\left.\mathrm{ZrSiO}_{4}\right)$. The phase composition of all sintered 
samples, presented in Table 2, showed multiphase patterns with the primary $\mathrm{Mg}_{2} \mathrm{Al}_{4} \mathrm{Si}_{5} \mathrm{O}_{18}$ phase accounting for approx. 56 to 81 vol. \%, which increased with increased mechanical activation of the powder mixture.

Table 2 Phase composition of sintered samples, obtained by XRD measurements, in vol. \%.

\begin{tabular}{|c|c|c|c|c|c|}
\hline Sample & $\mathbf{M g}_{2} \mathbf{A l}_{4} \mathbf{S i}_{5} \mathrm{O}_{18}$ & $\mathbf{A l}_{2} \mathrm{O}_{3}$ & $\mathrm{SiO}_{2}$ & $\mathbf{M g A l}_{2} \mathrm{O}_{4}$ & $\mathrm{ZrSiO}_{4}$ \\
\hline MAS-0 & 57.0 & 7.0 & 9.2 & 26.9 & - \\
\hline MAS-10 & 62.3 & 3.9 & 7.0 & 25.3 & 1.5 \\
\hline MAS-40 & 80.6 & - & 1.1 & 16.0 & 2.3 \\
\hline MAS-Te-0 & 57.2 & 9.0 & 7.7 & 26.1 & - \\
\hline MAS-Te-10 & 55.7 & 3.9 & 11.5 & 27.6 & 1.3 \\
\hline MAS-Te-40 & 78.2 & - & 1.2 & 19.0 & 1.6 \\
\hline
\end{tabular}

Phases of $\mathrm{Al}_{2} \mathrm{O}_{3}, \mathrm{SiO}_{2}, \mathrm{MgAl}_{2} \mathrm{O}_{4}$, and $\mathrm{ZrSiO}_{4}$ were observed as secondary phases. These phases are either remains from the initial mixture or intermediate products of the incomplete solid state reaction. The presence of the $\mathrm{ZrSiO}_{4}$ phase is probably caused by pollution from high energy milling (zirconia milling elements). The absence of Te-containing phases is probably caused either by evaporation of $\mathrm{TeO}_{2}$ up to $1350{ }^{\circ} \mathrm{C}$, or incorporation into the cordierite or magnesium silicate crystal lattice. Due to its empirical atomic radius of $140 \mathrm{pm}$, an atom of Te can replace an atom of magnesium, whose atomic radius is $150 \mathrm{pm}$; it cannot replace silicon or aluminum atoms because their radii are smaller, 110 and $125 \mathrm{pm}$, respectively [30]. If the solid solution were really formed, it would be manifested by slight shifting of peak intensities either to the left or right side in the diagram. However, changes in crystal lattice were not detected in the XRD patterns, so this statement remains only as an assumption. Furthermore, if XRD patterns showed no existence of Te, that doesn't mean there is no Te in the mixture (maybe a part is incorporated in the crystal lattice but the shift of peaks wasn't visible, and on the other hand, the limit of XRD measurement is around 3 mas. \%). Figure 4 shows XRD patterns of all sintered samples. All peaks are very intensive and sharp, indicating crystallization during the sintering process. 

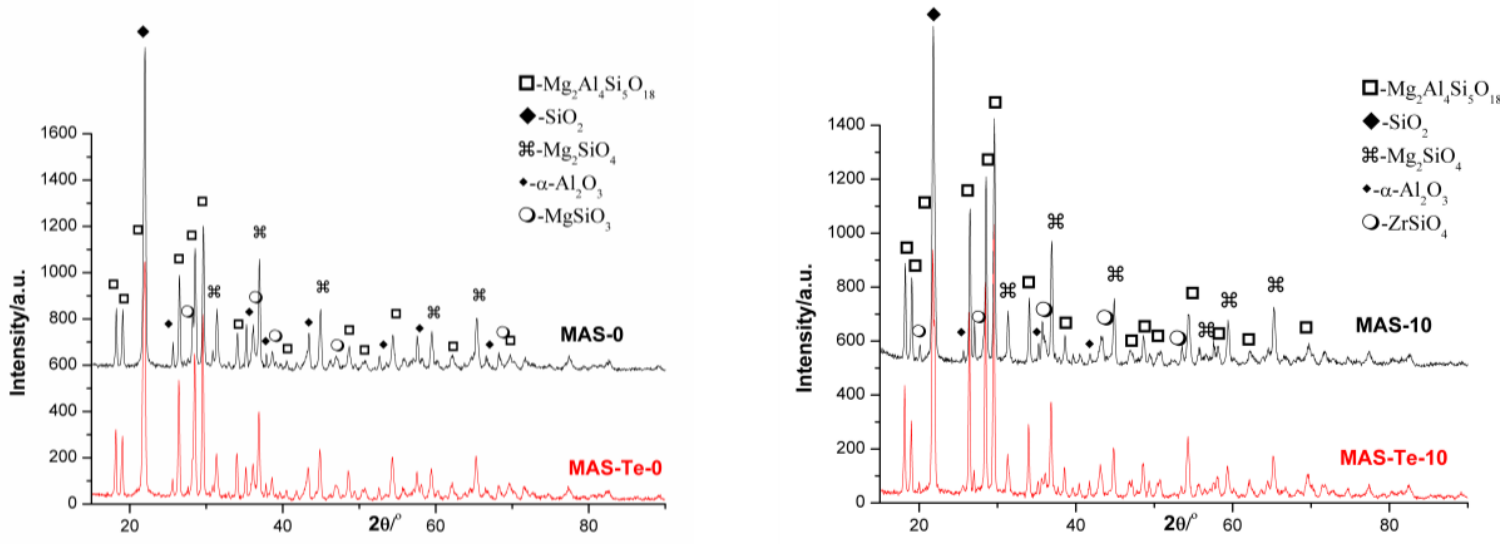

a)

b)

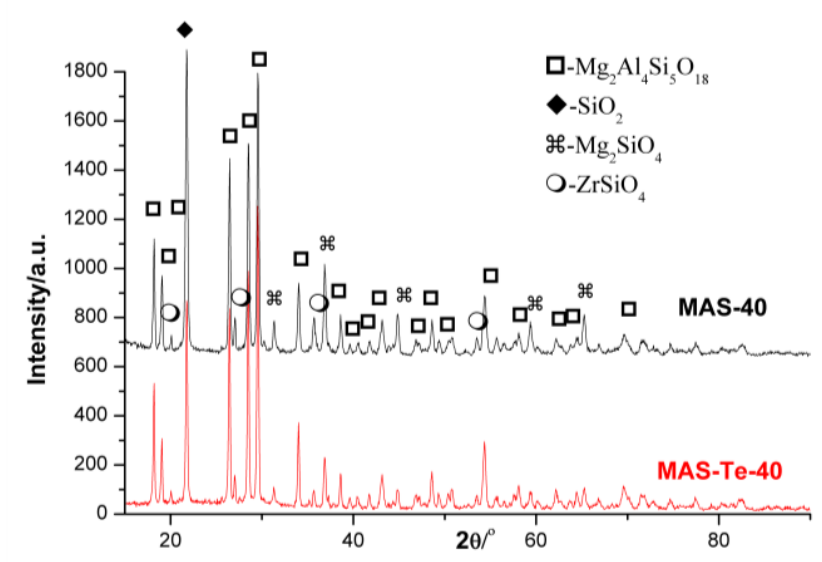

c)

Figure 4 XRD patterns of sintered a) non-activated mixtures, b) mixtures activated for 10 minutes, and c) mixtures activated for 40 minutes.

Scanning electron micrographs of all sintered samples are presented in Figure 5. Sintered non-activated samples possess a non-homogeneous microstructure with sintered parts originating from sintering of agglomerates and particles on the other side, along with open porosity. With the 10 minutes milling time prior to sintering, a more homogeneous microstructure is obtained, although the porosity is still present. The micrograph presented in Figure 5e) shows no visible porosity, the sintered MAS-40 sample has the most homogeneous microstructure, and it is very dense as well, in agreement with measured densities (see Table 1). The micrograph presented in Figure 5f) indicates very small closed pores probably originated from melted $\mathrm{TeO}_{2}$ phase. 

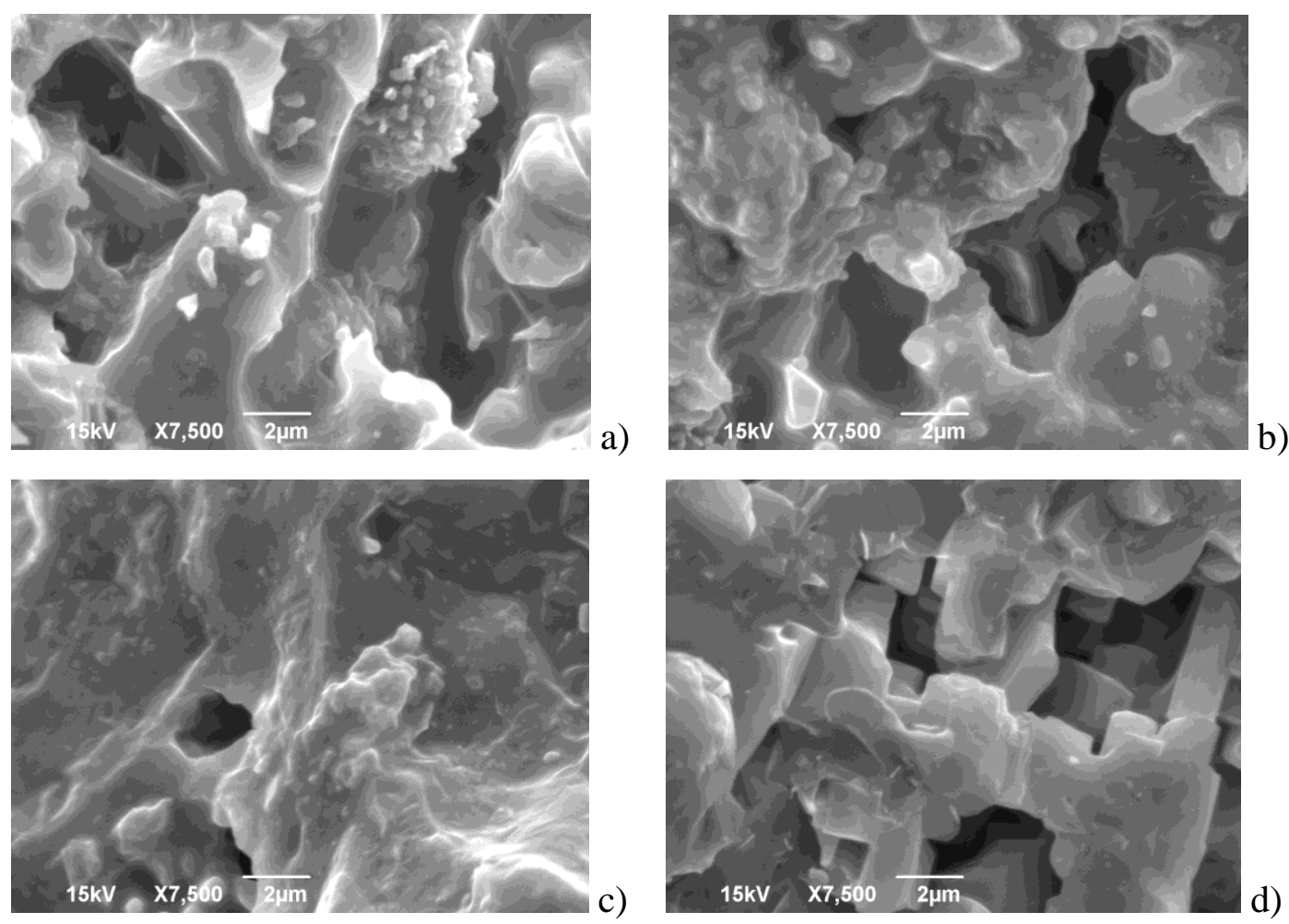

d)
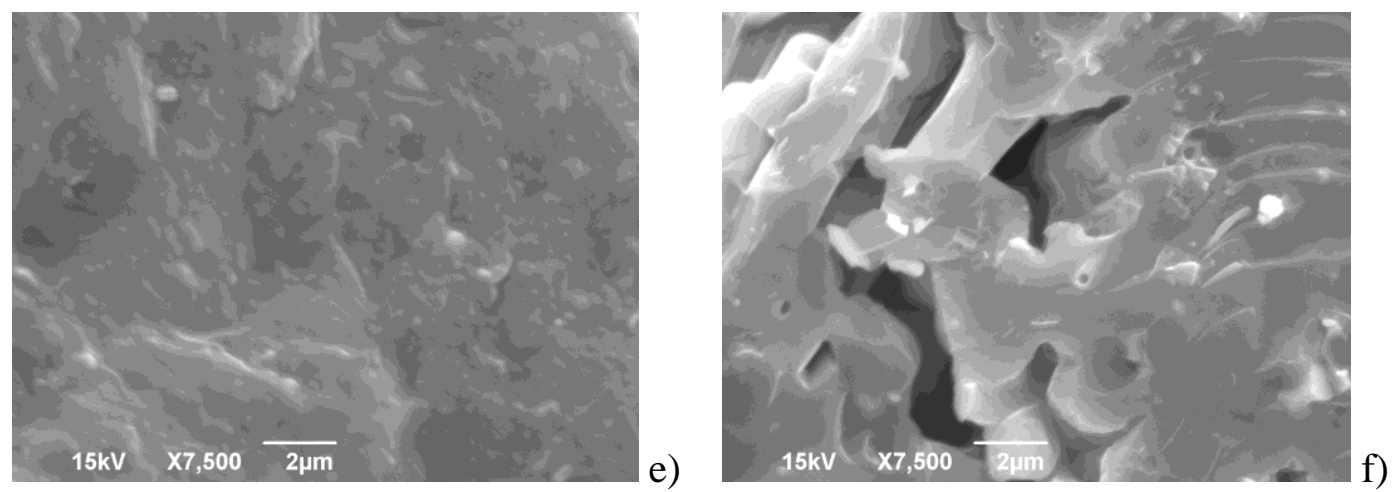

Figure 5 SEM micrographs of all sintered samples: a) MAS-0, b) MAS-Te-0, c) MAS-10,

d) MAS-Te-10, e) MAS-40, and f) MAS-Te-40.

Thermally activated processes in both MAS and MAS-Te samples were further investigated using DTA measurements. All curves possess an endothermic peak around $100{ }^{\circ} \mathrm{C}$, belonging to humidity evaporation. The temperature region around $570{ }^{\circ} \mathrm{C}$ corresponds to the structural $\alpha \rightarrow \beta$ phase transition in $\mathrm{SiO}_{2}$ (see Figure 6d) [35], where its position depends on the mechanical activation of the sample, as presented in Figure 6a). According to literature data, at normal pressure, trigonal quartz ( $\alpha$-quartz) will transform into hexagonal $\beta$-quartz at $573{ }^{\circ} \mathrm{C}$, upon further heating $\mathrm{SiO}_{2}$ will transform into hexagonal $\beta$-tridymite at $870{ }^{\circ} \mathrm{C}$, and later to cubic $\beta$-cristobalite at $1470{ }^{\circ} \mathrm{C}$. At $1705{ }^{\circ} \mathrm{C} \beta$-cristobalite finally melts [36]. However, tridymite usually does not form from pure $\beta$-quartz; one needs to add trace amounts of certain compounds to achieve this. So the $\beta$ quartz-tridymite transition is skipped and the sequence looks like this: 


\section{$573{ }^{\circ} \mathrm{C} \quad 1050{ }^{\circ} \mathrm{C} \quad 1705^{\circ} \mathrm{C}$}

\begin{tabular}{|c|c|c|}
\hline trigonal & hexagonal & cubic \\
\hline $2.65 \mathrm{~g} \mathrm{~cm}^{-3}$ & $2.53 \mathrm{~g} \mathrm{~cm}^{-3}$ & $2.20 \mathrm{~g} \mathrm{~cm}^{-3}$ \\
\hline
\end{tabular}

DTA measurements in the $1100-1400{ }^{\circ} \mathrm{C}$ temperature region show that MAS samples exhibit an endothermic peak followed by an exothermic peak and another endothermic peak, which can be attributed to the overlapping processes of chemical reaction of $\mathrm{Mg}_{2} \mathrm{Al}_{4} \mathrm{Si}_{5} \mathrm{O}_{18}$ phase formation and crystallization [37]. The temperature of cordierite formation is shifted towards higher temperatures with the increased heating rates, as shown in Figure 6c). Overall average activation energies of the first endothermic and the exothermic peak, calculated using Kissinger method [38], show that the mechanical activation has a significant effect, decreasing the activation energies to $1300-1100 \mathrm{~kJ} \mathrm{~mol}^{-1}$.
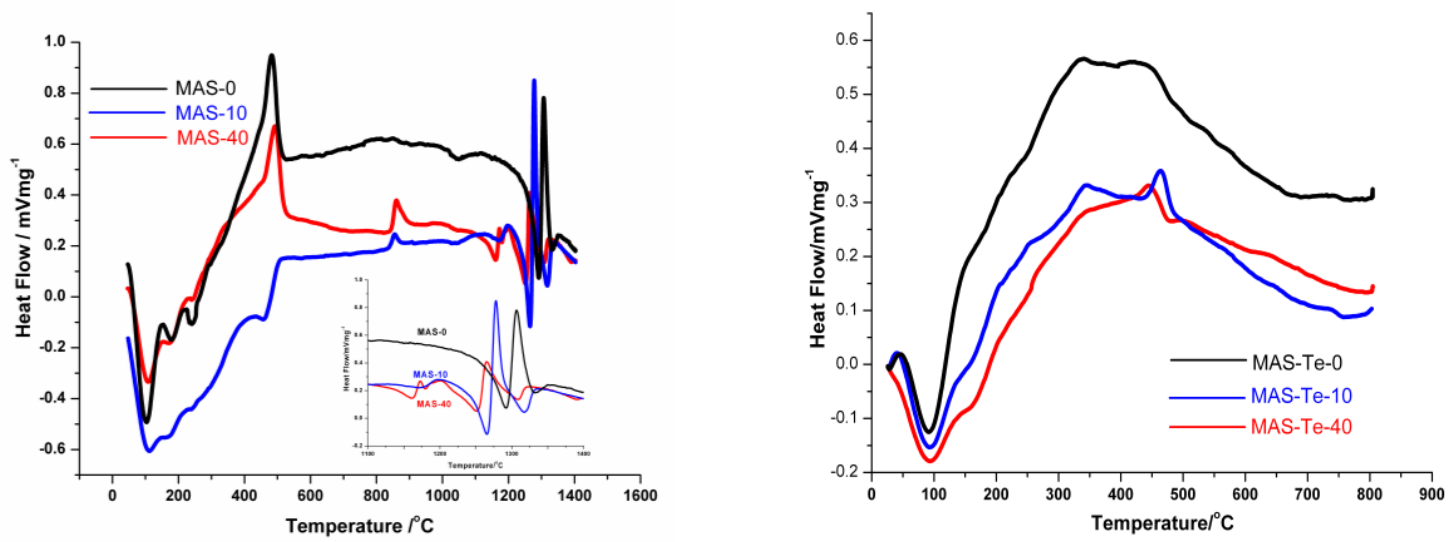

a)

b)
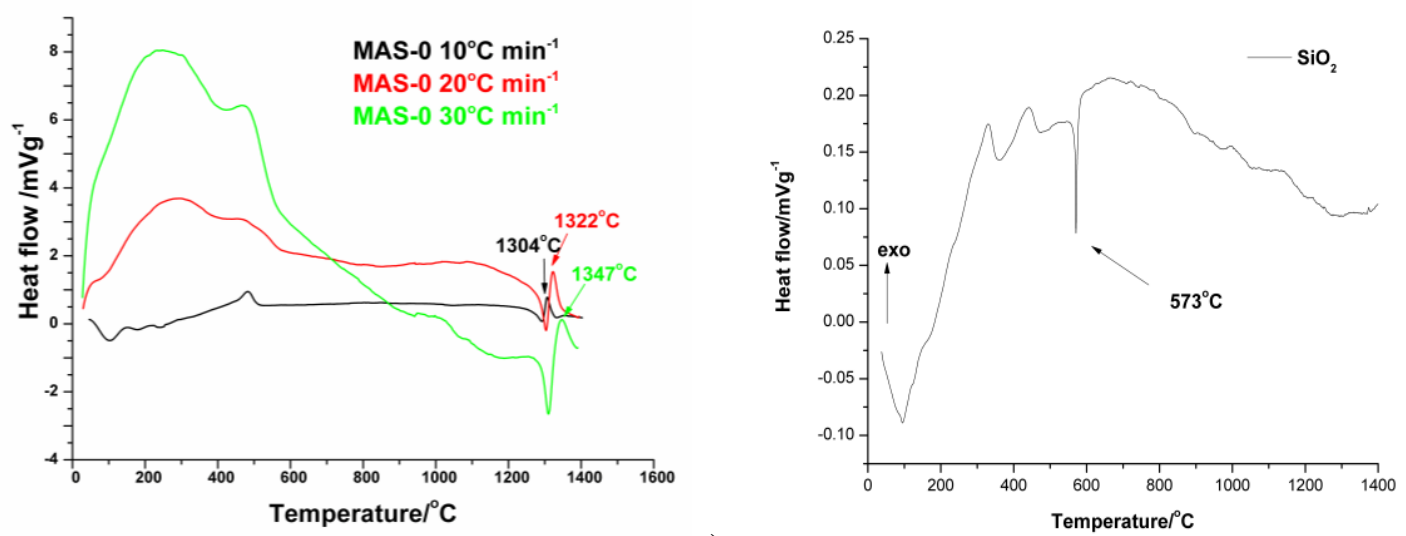

c)

Figure 6 DTA curves of a) MAS samples, b) MAS-Te samples with different mechanical activation times, c) MAS-0 with different heating rates, and d) $\mathrm{SiO}_{2}$ powder. 
A previous study of mechanically activated powders with addition of $\mathrm{MoO}_{3}$ produced values of the overall average activation energy in the same range [37], showing that the mechanical activation has a significant effect, decreasing the activation energy for the first process from 338 to $215 \mathrm{~kJ} \mathrm{~mol}^{-1}$, and for the second one from 212 to $70 \mathrm{~kJ} \mathrm{~mol}^{-1}$, correlated with the increase in powder reactivity. This can be attributed to the fact that the mechanical activation leads to reduction of particle size, it increases the contact surface between the particles, but also causes an increase in reactivity through introduction of surface defects. This also means that, in mechanically activated samples, there are a larger number of atoms simultaneously participating in processes of sintering and chemical reaction. Increase in reactivity due to the mechanical activation is also indicated by a shift of all processes to lower temperatures with increase in mechanical activation time, and the appearance of additional processes in the $1100-1200{ }^{\circ} \mathrm{C}$ region in MAS sample activated for 40 minutes, not observed in non-activated sample, which most likely represent the onset of $\mathrm{Mg}_{2} \mathrm{Al}_{4} \mathrm{Si}_{5} \mathrm{O}_{18}$ formation. This is consistent with the results of dilatometric measurements (Figure 3) and can also be correlated with significantly higher content of $\mathrm{Mg}_{2} \mathrm{Al}_{4} \mathrm{Si}_{5} \mathrm{O}_{18}$ phase in MAS-40 sample due to prolongation of the chemical reaction by this shift of the reaction onset to the 1100 $1200{ }^{\circ} \mathrm{C}$ temperature region.
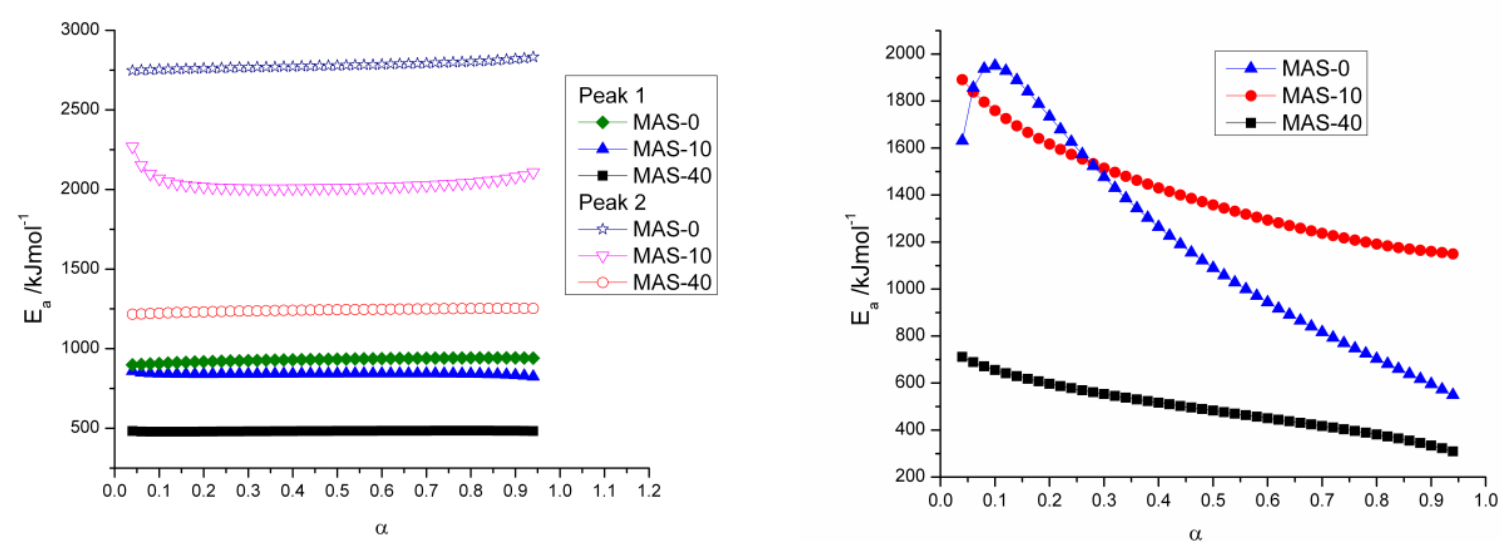

a)

Figure 7 Values of effective apparent activation energy for a) deconvoluted endothermic peak, and b) complex exothermic peak.

Figure 7 shows the values of the effective apparent activation energy for the deconvoluted endothermic peak and the complex exothermic peak, whose deconvolution was not feasible. The endothermic peak of the non-activated sample was deconvoluted into two single-step processes, which can be attributed to crystallization and formation of $\mathrm{Mg}_{2} \mathrm{Al}_{4} \mathrm{Si}_{5} \mathrm{O}_{18}$ phase. Although the mechanical activation increases the complexity of the overall peak, single-step processes corresponding to those observed in non-activated samples were successfully identified on 
deconvolution and Figure 7 shows values of effective apparent activation energy of these processes

in samples with different times of mechanical activation determined using Ortega method [40]. The process corresponding to peak 1 occurs at lower temperature, exhibits lower values of apparent activation energy, and can be attributed to the formation of $\mathrm{Mg}_{2} \mathrm{Al}_{4} \mathrm{Si}_{5} \mathrm{O}_{18}$ phase. The mechanical activation has a significant effect on this process. However, the difference between the two mechanically activated samples is considerably larger than between them and the non-activated sample, indicating that the prolonged mechanical activation has a significant effect on the process of $\mathrm{Mg}_{2} \mathrm{Al}_{4} \mathrm{Si}_{5} \mathrm{O}_{18}$ phase formation. This can be explained by the fact that the mechanical activation introduces surface defects in the precursor nanoparticles, which act as reaction sites for the formation of $\mathrm{Mg}_{2} \mathrm{Al}_{4} \mathrm{Si}_{5} \mathrm{O}_{18}$ phase. Prolonged mechanical activation creates both more nucleation sites and, due to decreased particle size, sites with higher surface energy, making the formation of $\mathrm{Mg}_{2} \mathrm{Al}_{4} \mathrm{Si}_{5} \mathrm{O}_{18}$ phase both easier, which is manifested through decrease in activation energy, and faster, which is manifested through significantly higher phase content of $\mathrm{Mg}_{2} \mathrm{Al}_{4} \mathrm{Si}_{5} \mathrm{O}_{18}$ phase in samples activated for 40 minutes (Table 2).

Peak 2 can be attributed to the sintering of the powder, and the decrease in apparent activation energy of this process is more continuous, which can be correlated with a relatively continuous decrease in particle size with prolonged mechanical activation of MAS samples (see Figure 1). This increases the contact surface between the particles, leading to a larger mass transport and easier sintering process.

\section{Conclusions}

Thermal analysis, using both dilatometric and DTA measurements, has shown that the onset of cordierite formation and sintering shifts towards lower temperatures by increase in mechanical activation time. In addition, dilatometry also shows that addition of $\mathrm{TeO}_{2}$ to the sample causes an additional shift towards lower temperatures, where these processes begin to occur as low as $1100{ }^{\circ} \mathrm{C}$. This indicates that the combination of additives and mechanical activation of the sample produces a synergistic effect to reduce the sintering temperature of cordierite and suggests that their use in concert should prove to be a more efficient method to reduce the sintering temperature of cordierite-based ceramics. The decreased values of effective apparent activation energy for deconvoluted endothermic peak of mechanically activated cordierite samples indicate that the mechanical activation leads to intensification of these processes, although the effects of prolonged mechanical activation are different for the sintering process than for the cordierite formation. This can be explained by different nature of these processes: cordierite formation, as a chemical reaction, is helped primarily by the increased concentration of surface defects and an increase in surface 
energy of these defect sites, while intensification of the sintering process is driven by the decrease

in grain size and the resulting increase in contact surface between them. Therefore, the effects of mechanical activation on formation of $\mathrm{Mg}_{2} \mathrm{Al}_{4} \mathrm{Si}_{5} \mathrm{O}_{18}$ phase become much more apparent after a longer period of mechanical activation, 40 minutes. Samples doped with $\mathrm{TeO}_{2}$ show higher porosity indicating that addition of $\mathrm{TeO}_{2}$ leads to obtaining a porous ceramic. Having in mind the growing needs for developing filters for diesel emission, filters for molten metals, etc., this method of using $\mathrm{TeO}_{2}$ as additive, and as pore forming agent simultaneously, could be a very interesting processing technique for preparation of cordierite-based porous filters.

\section{Acknowledgements}

This investigation was supported by the Serbian Ministry of Education, Science and Technological Development and it was conducted under the OI 172057 project. The authors acknowledge also the support of the Grant agency of Czech Republic under grant no. 17-05620S and support of the Ministry of Education, Youth and Sports of the Czech Republic under the project CEITEC 2020 (LQ1601).

\section{References}

1. Camerucci M. A, Urretavizcaya G, Cavalieri A. L. Sintering of cordierite based materials. Ceram. Int. 2003;29:159-168.

2. Taruta S, Hayashi T, Kitajima K. Preparation of machinable cordierite/mica composite by lowtemperature sintering. J. Eur. Ceram. Soc. 2004;24:3149-3154.

3. Camerucci M. A, Urretavizcaya, Cavalieri A. L. Mechanical behavior of cordierite and cordierite-mullite materials evaluated by indentation techniques. J. Eur. Ceram. Soc. 2001;21:11951204.

4. Moftah El-Buaishi N, Jankovic-Castvan I, Jokic B, Veljovic Dj, Janackovic Dj, Petrovic R. Crystallization behavior and sintering of cordierite synthesized by an aqueous sol-gel route. Ceram. Inter. 2012;38:1835-1841.

5. Obradović N, Filipović S, Đorđević N, Kosanović D, Pavlović V. B, Olćan D, Đorđevoć A, Kachlik M, Maca K, Microstructural and Electrical Properties of Cordierite-based Ceramics Obtained After Two-step Sintering Technique, Sci. Sinter. 2016;48:157-165.

6. Obradović N, Đorđević N, Peleš A, Filipović S, Mitrić M, Pavlović V. B. The Influence of Compaction Pressure on the Density and Electrical Properties of Cordierite-based Ceramics. Sci. Sinter. 2015;47:15-22. 
7. Wang X.-H, Deng X.-Y, Bai H.-L, Zhou H, Qu W.-G, Li L.-T. Two-Step Sintering of Ceramics with Constant Grain-Size, II: $\mathrm{BaTiO}_{3}$ and Ni-Cu-Zn Ferrite. J. Am. Ceram. Soc. 2006;89:438-443. 8. Obradović N, Filipović S, Đorđević N, Kosanović D, Marković S, Pavlović V, Olćan D, Đorđević A, Kachlick M, Maca K. Effects of mechanical activation and two-step sintering on the structure and electrical properties of cordierite-based ceramics. Ceram. Inter. 2016;42:9887-9898.

9. Obradović N, Đorđević N, Filipović S, Nikolić N, Kosanović D, Mitrić M, Marković S, Pavlović $\mathrm{V}$. Influence of mechanochemical activation on the sintering of cordierite ceramics in the presence of $\mathrm{Bi}_{2} \mathrm{O}_{3}$ as a functional additive. Powd. Technol. 2012;218:157-161.

10. Yin T, Park J. W, Xiong S, Physicochemical properties of nano fish bone prepared by wet media milling. LWT - Food Sci. Technol. 2015;64:367-373.

11. Nhi Truong D.Y, Kleinke H, Gascoin F, Preparation of pure Higher Manganese Silicides through wet ball milling and reactive sintering with enhanced thermoelectric properties. Intermetall. 2015;66:127-132.

12. Knickerbocker S. H, Kumar A. H, Herron L. W. Cordierite glass-ceramics for multilayer ceramic packaging, Am. Ceram. Soc. Bull. 1993;72:90-95.

13. Senguttuvan T. D, Kalsi H. S, Sharda S. K, Das B. K. Sintering behavior of alumina rich cordierite porous ceramics, Mater. Chem. and Phy. 2001;67:146-150.

14. Gass S. E, Sandoval M. L, Talou M. H, Martinez A.G. T, Camerucci M. A, Gregorová E, Pabst W. High temperature mechanical behavior of porous cordierite-based ceramic materials evaluated using 3-point bending, Proceed. Mater. Sci. 2015;9:254-261.

15. Okada K, Isobe T, Katsumata K, Kameshima Y, Nakajima A, MacKenzie K. J. D. Porous ceramics mimicking nature-preparation and properties of microstructures with unidirectionally oriented pores, Sci. Technol. Adv. Mater. 2011;12:690-701.

16. Pavlović V. P, Stojanović B. D, Pavlović V. B, Živković L. M, Ristić M. M. Low temperature sintering of mechanically activated $\mathrm{BaCO}_{3}-\mathrm{TiO}_{2}$, Sci. Sinter. 2002;34:73-77.

17. Obradović N, Filipović S, Pavlović V. B, Maričić A, Mitrović N, Ristić M. M. Sintering of mechanically activated magnesium-titanate and barium-zinc-titanate ceramics, Sci. Sinter. 2011;43:145-151.

18. Tunç $T$, Demirkıran A. Ş. The effects of mechanical activation on the sintering and microstructural properties of cordierite produced from natural zeolite, Powder Technol. 2014;260:7-14.

19. Nebojša Labus, Zorka Vasiljević, Obrad Aleksić, Miloljub Luković, Smilja Marković, Vladimir Pavlović, Slavko Mentus, Maria Vesna Nikolić. Characterisation of $\mathrm{Mn}_{0.63} \mathrm{Zn}_{0.37} \mathrm{Fe}_{2} \mathrm{O}_{4}$ Powders After Intensive Milling and Subsequent Thermal Treatment, Sci. Sinter. 2017;49:455-467. 20. Zdujuć M, Poleti D, Jovalekić Č, Karanović Lj. J. Non-Ctystall. Sol. 2006;352:3058-3068. 
21. Tkačova K. Mechanical activation of minerals, Elsevier, Amsterdam, 1989: 49.

22. Yangyun S. Brook R. J. Sci. Sinter. 1985;17:35-47.

23. Avvakumov E. G. Mechanical methods of activation of chemical processes. Nauka Sib. Otb., Novosibirsk, 1986:95.

24. Li X, Shih W. H. J. Am. Ceram. Soc. 1997;80:2844-2851.

25. Fotoohi B, Blackburn S. Effects of mechanochemical processing and doping of functional oxides on phase development in synthesis of cordierite. J. Eur. Ceram. Soc. 2012;32:2267-72.

26. Luo L, Zhou H, Xu C. Microstructural development on sol-gel derived cordierite ceramics doped $\mathrm{B}_{2} \mathrm{O}_{3}$ and $\mathrm{P}_{2} \mathrm{O}_{5}$. Mater. Sci. Eng. 2003;B99:348-51.

27. Yalamac $\mathrm{E}_{s}$ Akkurt $\mathrm{S}$. Additive and intensive grinding effects on the synthesis of cordierite. Ceram. Inter. 2006;32:825-32.

28. Liu C, Liu L, Tan K, Zhang L, Tang K, Shi X. Fabrication and characterization of porous cordierite ceramics prepared from ferrochromium slag, Ceram. Inter. 2016;42:734-742.

29. Đorđević N, Obradović N, Kosanović D, Mitrić M, Pavlović V P. Sintering of Cordierite in the Presence of $\mathrm{MoO}_{3}$ and Crystallization Analysis, Sci. Sinter. 2014;46:307-313.

30. "WebElements, https://www.webelements.com, accessed October 2018."

31. Blagojevic V. ThermV v0.2, https://sourceforge.net/projects/thermv/

32. Maca K, Pouchly V, Boccaccini A. R. Sintering Densification Curve - a Practical Approach For Its Construction From Dilatometric Shrinkage Data, Sci. Sinter. 2008;40:117-122.

33. Filipovic S, Obradovic N, Djordjevic N, Kosanovic D, Markovic S, Mitric M, Pavlovic V. Uticaj mehanicke aktivacije na sistem $\mathrm{MgO}-\mathrm{Al}_{2} \mathrm{O}_{3}-\mathrm{SiO}_{2}$ u prisustvu aditiva $\mathrm{TeO}_{2}$. Tehnika-Novi materijali, 2016;25:797-802.

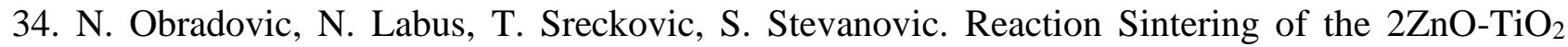
System, Sci. Sinter. 2007;39:127-132.

35. Tucker M G, Keene D A, Dove M T. A detailed structural characterization of quartz on heating through the $\alpha-\beta$ phase transition. Mineral Mag. 2001;65:489-507.

36. Source: http://www.quartzpage.de/gen_mod.html.

37. Obradović N, Đorđević N, Filipović S, Marković S, Kosanović D, Mitrić M, Pavlović V. Reaction kinetics of mechanically activated cordierite-based ceramics studied via DTA. J. of Therm. Anal. and Calorim. 2016;124(2):667-73.

38. Kirsever D, Karakus N, Toplan N, Toplan H O. The cordierite formation in mechanically activated talc-kaoline-alumina-basalt-quartz ceramic system. Acta Phys Polonica A. 2014;127:1042-4.

39. Kissinger H. E. Reaction kinetics in differential thermal analysis, Anal. Chem. 1957;29:1702. 
40. Ortega A. A simple and precise linear integral method for isoconversional data, Thermochim. Acta. 2008;474:81.

2

3

4

5 